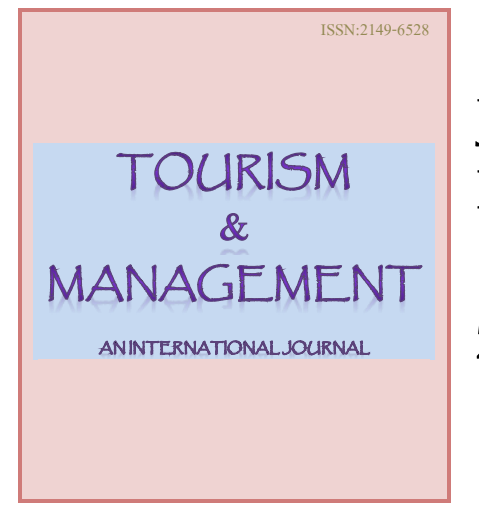

Journal of Tourism and Management Research ISSN: 2149-6528

\author{
2017 Vol. 2, Issue.1
}

\title{
HRM Practices Used in Hotel Industry in Relation to Employee Satisfaction: A Study with special reference to Chandigarh
}

\begin{abstract}
This study aims to compare the satisfaction of hotel employees in accordance with the human resource management (HRM) practices adopted by hospitality industry in an Indian province named Chandigarh. The data for this research study was gathered from primary as well as secondary sources. Sample includes employees from leading hotels of Chandigarh. Results of study revealed that the importance of employee satisfaction and work motivation is growing all the time in the companies. Findings of this study can be used to increase the performance of Hotels of various other cities of the country too.
\end{abstract}

Keywords: Satisfaction, Effectiveness, Motivation, Productivity, Hospitality

Vinay Chamoli, Associate Prof.Dr. (Corresponding Author). Maharaja Agrasen School of Management, Maharaja Agarsen University Baddi , Himachal Pradesh, India.

Email: chamoli79@gmail.com

Sandeep Paatlan, Assistant Prof.Dr. Maharaja Agrasen School of Management, Maharaja Agarsen University Baddi , Himachal Pradesh, India.

Email: sandeep.paatlan@gmail.com 


\section{Introduction}

The industrial and business sectors of various countries specially developing countries including India (where per capita income is very low) are facing the problem of job dissatisfaction among the employees and high rate of turnover. Job Satisfactionis regard to one's feeling or state of mind regarding the nature oftheir work. Job satisfaction can be influenced by variety of factors such as kind of supervision, organization policies \& administration, salary \& quality of life etc. Employers have a need to keep employee from leaving and going to work for other organizations (Dawson et al., 2011). The best way of retaining employees is to provide the job satisfaction and opportunities to build up their careers. "The good hope is hard to find, is even truer these days than ever before because the job market in becoming increasingly tight". In this paper, characteristics of work culture in hotels has been analyzed and the effect on employee satisfaction are estimated. It also discuss the importance of understanding different strategies in use and their effects on job satisfaction. The main aim was to find out the various strategies of employee satisfaction in leading hotels in Chandigarh, and to find out possible aspects for improvements through Human Resource strategies. The analysis of the research results is based on various theories in the field of Human Resource Management. Different motivation, leadership and cultural theories are used in explaining and analyzing the result. The first and major motive of the study is to identify the different HRM practices used by the hotel industry specifically in Chandigarh and Mohali and Panchkula region. The second objective of the study is to analysis the different variables and their impact on employee's satisfaction. The impact of HRM practices on organizational performance has emerged as the dominant research issue in the HRM field. A few scholars have studied the impact of HRM practices on performance in the Hotel \& Tourism industry. Only few researchers have addressed the HRM practices and their outcomes in Hotel \& Tourism industry in India and none study HRM practices, their outcomes and impact of HRM practices on job satisfaction among employees of leading hotels in Chandigarh. Therefore, this study addresses this gap in the literature in relation to Hotel industry in Chandigarh. This study attempts to find solution for the HRM practices of hotels in Chandigarh including how do HRM practices impact employee satisfaction, commitment and retention? And how do HRM practices impact performance of leading hotel brands in Chandigarh? Therefore, findings of this study are helpful to describe the HRM outcomes (such as employee motivation, employee commitment, employee retention etc.) of HRM practices of leading hotels in Chandigarh, and their interrelationshi with employee's satisfaction. The findings of this research are helpful for managers to examine the success of HR practices which are currently implemented by them.

\section{Literature Review and Hypotheses}

Dawson et al. (2011) pointed out that, companies are aware of the importance of satisfaction in hotel workers. Studies have been performed to understand the relationship between satisfaction and: (a) addictive behaviors (Santos \& Paiva, 2007); (b) service (Rebouças et al., 2007); (c) physical health (Leite \& Carvalho, 2011); (d) performance ( Gu \& Siu, 2008); (e) empowerment (Chen, 2006); (f) individual factors or general job satisfaction (Almeida et al., 2012); (g) work-family conflict (Qu \& Zhao, 2012); (h) organizational commitment (Chen, 2006; (i) hospitality (Fisher \& McPhail, 2011); (j) workers, customers, and financial performance (Chi \& Gursoy, 2009); (k) work and intention to quit (Chen, 2012); (l) selfesteem, self-efficacy, and emotional stability (Judge \& Bono, 2001); (m) national culture (Sledge et al., 2008); (n) flexibility (Lee et al., 2011); and (o) virtual work (Golden \& Veiga, 2008). However, other studies have attempted to understand the importance of satisfaction in the context of HRM- Human resourse Management in general. For example, Armstrong 
(2006) defines Human Resource Management (HRM) as a strategic and coherent approach to the management of an organization's most valued assets - the people working there who individually and collectively contributes to the achievement of the objectives.

Wright et al. (1994) distinguished between an organization's human resources (the skilled and experienced employees) and human resources systems. They argued that an organization's human resources have a greater potential to generate value on a sustainable basis. But to create value, the human resources must exhibit high levels of skill and the willingness, motivation, and commitment to exhibit productive behavior that are generated by the human resource practices. Barney (1986) argued that human resources can provide a source of sustained competitive advantage when four basic requirements are met, that is, through valuable, rare, inimitable and well organized human resources. As a result, it is important that a firm adopts human resource management (HRM) practices that make best use of its employees.

Pfeffer (1995) proposed that seven HRM practices: employment security, selective hiring of new personnel, self-managed teams and decentralization of decision making as the basic principles of organization design, comparatively high compensation contingent on organizational performance, extensive training, reduced status distinctions and barriers, including dress, language, office arrangements, and wage differences across levels, extensive sharing of financial and performance information throughout the organization are characteristic of successful organizations. Hoppock (1935) indicates that job satisfaction means the mental, physical andenvironmental satisfaction of employee and the extent of job satisfaction can be known by inquiring employees about the job satisfaction extents. Solly and Hohenshil (1986) stated "Job satisfaction is defined as an attitudeindividuals hold about their work consisting of a general or global factor of satisfaction as well as a collection of specific factors related to sources of work reinforcement" (p. 119). "Job satisfaction is defined as "the extent to which people like (satisfaction) or dislike (dissatisfaction) their jobs" (Spector, 1997, p. 2). This definition suggests job satisfaction is a general or global affective reaction that individuals hold about their job.

In their book on theories of job satisfaction, Campbell et al. (1970) divide the present-day theories of job satisfaction into two groups, content theories which give an account of the factors that influence job satisfaction and process theories that try to give an account of the process by which variables such as expectations, needs, and values relate to the characteristics of the job to produce job satisfaction.

On the basis of our literature review, this study created some hypotheses which are directly related to our objective of the study. Following are the four hypotheses or the factors responsible for the employee satisfaction in hotel industry;

Hypothesis 1: Providing training for employees is positively related to higher employee satisfaction.

Hypothesis 2: Provision of performance-based compensation is positively related to higher employee satisfaction.

Hypothesis 3: Employee involvement in decision making is positively related to higher employee satisfaction.

Hypothesis 4: Well-functioning grievances handling system is positively related to higher employee satisfaction.

\section{Methodology}

\subsection{Sampling and Data Collection}

The segmented area of study was leading hotel of Chandigarh and nearby.The target 
organizations of the employee satisfaction survey were the leading hotels like Taj,J.WMarriott, Mountview, ParkPlaza, Hometel\& Lemon tree in Chandigarh. Employees from all the three levels of management i.e Top,Middle and Bottom were involved in the research work.The employees from all the various departments of the hotels were drawn in during the survey so that the fair result can be obtained in context of the research question. The total number of respondents were 209. This research was quantitative research means the process of explaining some kind of phenomena mathematically analyzing numerical data (Muijs, 2004, 1). In every research, quantitative or qualitative, the first step is to define the phenomena. Without the phenomena the research does not exist. In the quantitative research the data must be in a numerical form which is explained by the fact that in quantitative research the results are analyzed by using mathematical methods. A quantitative research method is for example a questionnaire is used in carrying out this research. The study is carried out by both secondary and primary data. The secondary source of data is collected through extensive literature study. The primary data is collected through structured questionnaire.

\subsection{Questionnaire Development and Measures}

The purpose of this survey is to explore the HR strategies adopted by hospitality sector in India. All the Statements in this survey have been prepared after extensive review of literature. This survey consists of two parts. The first part of the survey was composed of demographic questions related to age, gender, education, and length of work/ job with the organization. Second part of survey consists of 34 statements related to HR strategies being practiced by hospitality industry in India. These statements are related to selection and recruitment of employees, their training \& development, performance evaluation, employee's promotion, grievances handling system, compensation and social benefits from the job. Obviously, the success of this sacred mission shall exclusively depend on the free and frank views of the respondents with regard to their job in their respective Hotels. The information provided herein by you will be kept strictly confidential and, to be used only in statistical exercises.

\subsection{Data Analysis}

To check the reliability of the scale the cronbach alpha test is carried out. Pearson correlation coefficient test is also carried out to find the level of relationship between to the two variables. The study also used regression analysis to study the relationship between the dependent variable and independent variable. All these test were analyzed with the help of Statistical Package for the Social sciences 21 (SPSS). The basic data is shown with the help of pie-charts, bar diagrams, histograms and with percentage method.

\section{Analysis and Results}

\subsection{Descriptive Statistics}

The sample was included 209 respondents who are working in different sections of various departments in leading hotels of Chandigarh. Table 1 illustrates the gender composition of respondents.

Table 1: Gender Composition of Respondents.

\begin{tabular}{|c|c|c|}
\hline Gender & Frequency & Percent (\%) \\
\hline Female & 97 & 46.4 \\
\hline Male & 112 & 53.6 \\
\hline
\end{tabular}




\begin{tabular}{|c|c|c|}
\hline Total & 209 & 100.0 \\
\hline
\end{tabular}

Age distribution of respondents is presented in table 2. It shows that most of respondents are in age category of 21-30. That is, $35.4 \%$ of respondents. 3.8 are in age category of 51 or older.

Table 2: Age Distribution of Respondents.

\begin{tabular}{|l|l|l|}
\hline Age & \multicolumn{1}{|c|}{ Frequency } & Percent (\%) \\
\hline 51 or older & 8 & 3.8 \\
\hline $40-51$ & 35 & 16.7 \\
\hline $30-40$ & 58 & 27.8 \\
\hline $21-30$ & 74 & 35.4 \\
\hline Under 21 & 34 & 16.3 \\
\hline Total & 209 & 100. \\
\hline
\end{tabular}

Respondents were asked to indicate their highest education qualification. Collected data on the highest education qualification is presented at the table 3. According to the given data in the table 3, 3 year hotel management degree has recorded as the highest education qualification of most of the respondents in the sample. That is, 91 employees have passed 3 year degree.Also, the organizational service periods of the respondents were shown in table 3 .

Table 3: Education Qualification and Service Periods of Respondents.

\begin{tabular}{|l|l|l|l|l|l|}
\hline $\begin{array}{l}\text { Highest Education } \\
\text { Qualification }\end{array}$ & Frequency & $\begin{array}{l}\text { Percent } \\
(\boldsymbol{\%})\end{array}$ & Service period & Frequency & Percent (\%) \\
\hline Diploma & 88 & 42.1 & $\begin{array}{l}\text { More than eight } \\
\text { years }\end{array}$ & 11 & 5.3 \\
\hline Degree -3 Years & 91 & 43.5 & $5-8$ years & 16 & 7.7 \\
\hline Degree -4 Years & 9 & 4.4 & $3-5$ years & 18 & 8.6 \\
\hline Post Graduate & 21 & 10.0 & $0-3$ years & 164 & 78.4 \\
\hline Total & 209 & 100.0 & Total & 209 & 100.0 \\
\hline
\end{tabular}

\subsection{Reliability Testing}

Cronbach's alpha has been used to measure the reliability of items in this study. Cronbach's Alpha coefficient is a statistic for internal reliability, values ranging from 0 to 1 , and higher values indicate greater reliability. Table 4 presents the results of reliability test for each HRM Practices. It could be observed that all of the alpha values are more than 0.6. According to table 4, alpha value for grievances handling is 0.911 which is the highest alpha value among HR Practices. Computed alpha values exceed 0.7 for three HRM practices. They are grievances handling, performance appraisal and recruitment \& selection. Results show that Cronbach's alpha is 0.722 for all the dimensions ( 34 dimensions) of HRM practices . These statistics reveal that internal consistency of items to the concept is good. 
Table 4: Reliability Statistics for Six HRM Practices.

\begin{tabular}{|c|c|c|}
\hline HRM practice & N: of Items & Cronbach's Alpha \\
\hline Recruitment \& Selection Practices & 6 & 0.711 \\
\hline Training \& Development Practices & 4 & 0.630 \\
\hline Performance Appraisal practices & 5 & 0.797 \\
\hline Compensation and social benefits & 11 & 0.613 \\
\hline Promotion practices & 4 & 0.652 \\
\hline Grievances Handling & 4 & 0.911 \\
\hline
\end{tabular}

Table 5 below indicates the Cronbach's alpha values for each HR outcomes i.e., employee satisfaction, commitment and retention. It could be observed that all the alpha values are more than 0.74 . Therefore, internal consistency of items to the concept is good. Also itindicates the alpha values for all the dimensions of HR outcomes. It is 0.761 .

Table 5: Reliability statistics for HR outcomes

\begin{tabular}{|l|l|l|}
\hline \multicolumn{1}{|c|}{ HR Outcomes } & N: of Items & Cronbach's Alpha \\
\hline Employee satisfaction & 8 & 0.767 \\
\hline Employee commitment & 2 & 0.743 \\
\hline Employee retention & 9 & 0.774 \\
\hline & 19 & 0.761 \\
\hline
\end{tabular}

\subsection{Correlation Analysis}

Correlation is tool which depicts the amount of two or more variables fluctuate together. There are generallysix type's correlation positive and negative correlation, no correlation, perfect correlation, strong correlation and weak correlation. In positive correlation variables increase or decrease in a parallel level. In no correlation there is no relationship between increase and decrease of variables. Perfect correlation occurs when there is a functional dependency between the variables.In strong correlation the closer the points are located to one another on the line. A correlation is weaker the farther apart the points are located to one another on the line is called weak correlation (Tabachnick and Fidell, 1996). However, Regression analysis is a scientifically method of sorting out which of those variables does indeed have an effect. It responses the queries: Which factors matter most? Which can we overlook? How do those factors interrelate with each other? And, perhaps most importantly, how certain are we about all of these factors (Gallo, 2016). Pearson correlation coefficients 
illustrate that there is positive relationship between all the independent variables and employee satisfaction. Thus, hypothesis 1 was accepted that providing training for employees is positively related to higher employee satisfaction.

Table 6: Results of Pearson Correlations for Dimensions of Training and Employee Satisfaction.

\begin{tabular}{|l|l|l|}
\hline S.No. & Independent variables (Training) & $\begin{array}{l}\text { Dependent variable (Employee } \\
\text { Satisfaction) }\end{array}$ \\
\hline 1 & Opportunities to learn \& grow & $0.261^{* *}$ \\
\hline 2 & Getting training needed to do job well & $0.360^{* *}$ \\
\hline 3 & Training for promotion & $0.233^{* *}$ \\
\hline 4 & Training match with the job & 0.090 \\
\hline
\end{tabular}

Table 6 demonstrates the correlation coefficient for dependent variable i.e., employee satisfaction and independent variables i.e., the four dimensions of training and development practice. Correlation coefficients of three independent variables are significant at the significance level of $1 \%$. In connection with hypothesis 2 , regression analysis was conducted with employee satisfaction as the dependent variable and the four dimensions of training and development as the independent variables. The adjusted $\mathrm{R}$ square value is 0.132 that reveals $13.2 \%$ of total variance in employee satisfaction is explained by training variable. Results show that the $F$ value is 8.896 that is significant at $p=0.000$, suggesting that four dimensions of training variable have significantly explained the $13.2 \%$ of the variance in employee satisfaction. Regression results show that getting training needed to do job well $(\mathrm{t}=4.081 ; \mathrm{p}=0.000)$, emerged as the most significant variable in explaining the variance in employee satisfaction. This value is significant at $1 \%$ significance level. That is, getting training needed to do job well variable had the strongest effect on employee satisfaction with a standardized coefficient beta of 0.295 . Regarding hypothesis 2 , the null hypothesis is that, provision of training is not positively related to higher employee satisfaction. Results of regression analysis support the hypothesis 2 , hence null hypothesis is rejected and its alternative hypothesis that provision of training is positively related to higher employee satisfaction is supported by the data set. Results of the correlation analysis show that, Pearson correlation coefficient is 0.439 , and the $p$-value for two- tailed test of significance is 0.000 . From these figures it canbe concluded that there is strong positive relationship between performance-based compensation and employee satisfaction, as expected. Thus hypothesis 2 was accepted that provision of performance-based compensation is positively related to higher employee satisfaction:

Table 7: Results of Regression Analysis for Employee Satisfaction.

\begin{tabular}{|l|l|}
\hline Regression coefficient (B) & 0.022 \\
\hline Standard error (SE) & 0.003 \\
\hline t-value & 7.039 \\
\hline
\end{tabular}




\begin{tabular}{|l|l|} 
& \\
\hline Significance level $(p)$ & 0.000 \\
\hline Standardized Coefficient $(\beta)$ & 0.439 \\
\hline Adjusted $\mathrm{R}^{2}$ & 0.189 \\
\hline F value & 49.552 \\
\hline
\end{tabular}

Regression analysis was conducted with employee satisfaction as the dependent variable and performance-based compensation as the independent variable. The adjusted $\mathrm{R}$ square value is 0.189 and $\mathrm{F}=49.552(\mathrm{p}<0.000)$ that reveals the performance-based compensation can predict $18.9 \%$ of the variance in employee satisfaction. Regression coefficient (B) was $0.022(0.003)$ which was significantly different from zero $(\mathrm{t}=7.039 ; \mathrm{p}=0.000)$ at $1 \%$ significance level. Therefore, results of regression analysis support the hypothesis 3 . Thus null hypothesis is rejected and its alternative hypothesis that provision of performance-based compensation is positively related to higher employee satisfaction is supported.

Table 8: Results of Regression Analysis.

\begin{tabular}{|l|l|}
\hline Regression coefficient (B) & 0.025 \\
\hline Standard error (SE) & 0.003 \\
\hline t-value & 8.224 \\
\hline Significance level $(p)$ & 0.000 \\
\hline Standardized Coefficient $(\beta)$ & 0.496 \\
\hline Adjusted $\mathrm{R}^{2}$ & \\
\hline F & 0.243 \\
\hline
\end{tabular}

Results of the correlation analysis show that, Pearson correlation coefficient is 0.496 , and the $p$-value for two- tailed test of significance is 0.000 . This correlation issignificant at the significance level of $1 \%$. This figure 0.496 , suggests that there is a positive relationship between employee involvement in decision making and employee satisfaction, as expected. Results of regression analysis are shown in table 8. Regression analysis was conducted with employee satisfaction as the dependent variable and employee involvement in decision making as the independent variable. The adjusted $\mathrm{R}^{2}$ is 0.243 and $\mathrm{F}$ value is $67.640(\mathrm{p}=$ 0.000 ) that reveals employee involvement in decision making variable has significantly explained the $24.3 \%$ of the variance in employee satisfaction. Regression coefficient (B) is $0.025(0.003)$ which is significantly different from zero $(\mathrm{t}=8.224 ; \mathrm{p}=0.000)$ at the $1 \%$ significance level. Therefore, results of regression analysis support the hypothesis 3 . Thus null hypothesis is rejected and its alternative hypothesis that employee involvement in decision making is positively related to higher employee satisfaction is supported by the data 
from leading hotels in Chandigarh.

Table 9: Results of Pearson Correlations for Employee Satisfaction.

\begin{tabular}{|l|l|l|}
\hline No: & $\begin{array}{l}\text { Independent variables( dimensions of Grievances } \\
\text { handling) }\end{array}$ & $\begin{array}{l}\text { Dependant variable (Employee } \\
\text { satisfaction) }\end{array}$ \\
\hline 1 & Clear \& formal procedures for GH & -0.020 \\
\hline 2 & Supervisor handles work-related issues satisfactorily & 0.049 \\
\hline 3 & Availability of supervisor & 0.012 \\
\hline 4 & supervisor delegates work effectively & 0.127 \\
\hline
\end{tabular}

Table 9 indicates the correlation coefficients for dependant variable i.e., employee satisfaction and independent variables i.e., four dimensions of grievances handling. Results of correlation analysis demonstrate that there is negative relationship between all the independent variables and employee satisfaction. From these numbers, it is concluded that there is an unexpected negative correlation between grievances handling system of Hotels of Chandigarh and employee satisfaction, but that this finding is very uncertain. Regression analysis was conducted with employee retention as the dependent variable and four dimensions of grievances handling as the independent variables. The adjusted $\mathrm{R}$ square value is 0.025 that reveals that $2.5 \%$ of total variance in employee satisfaction is explained by four dimensions of grievances handling jointly. Results shows that the F value is 2.338 ( $\mathrm{p}=0.057)$, suggesting that four dimensions of grievances handling have significantly explained the $2.5 \%$ of variance in employee satisfaction at $10 \%$ significance level. Supervisor delegates work effectively is significant at $1 \%$ significance level with negative $t$ value $(\mathrm{t}=-2.892 ; \mathrm{p}=0.004)$. Availability of supervisor $(\mathrm{t}=1.785 ; \mathrm{p}=0.076)$ emerged as the significant variable in explaining the variance in employee satisfaction at $10 \%$ significance level . Regarding hypothesis 4, the null hypothesis is that, grievances handling is not positively related to higher employee satisfaction. Results of regression analysis do not support the hypothesis 4 . Thus null hypothesis is not rejected but its alternative hypothesis that grievances handling system of leading hotels in Chandigarh is positively related to higher employee satisfaction is rejected. Therefore, collected data from employees through structured questionnaire does not support the alternative hypothesis that grievances handling system of leading hotels in Chandigarh is positively related to higher employee satisfaction in leading hotels in Chandigarh.

\section{Conclusion, Implications, and Limitations}

Very few researchers have addressed the HRM practices and their outcomes in Hotels in Chandigarh and none of the study have highlighted HRM practices, their outcomes and impact of HRM on relationship of employee satisfaction in Hotels of Chandigarh.. Therefore, this study addressed this gap in the literature in relation to Hotels in Chandigarh. Findings of this study are helpful to describe what HRM practices are positively related with HR outcomes i.e., employee satisfaction, employee commitment of Hotels in Chandigarh. Hence, findings of this research are helpful to managers to examine the success of HR practices which are currently implemented by them and to identify HRM 
outcomes of them. Findings of this study are helpful to describe what HRM practices are positively related with HR outcomes i.e., employee satisfaction, employee commitment of Hotels in Chandigarh.

Hence, findings of this research are helpful to managers to examine the success of HR practices which are currently implemented by them and to identify HRM outcomes of them. The results of this study revealed that bundles of HRM practices are positively related to betteremployee satisfaction. This result is consistent with that of Jackson \&Schuler, (1992), Eskildsen\&Nussier, (2000) and Boselie\&Wieles, (2002). This means that effective HRM practices lead to employee satisfaction. Results revealed that only four dimensions of HRM practices emerged as the predictors of employee satisfaction in the case of Hotels in Chandigarh. These practices include compensation and social benefits, performance appraisal, training and development, and recruitment and selection. Compensation and social benefits had the strongest significant effect on employee satisfaction. The current study has some limitations as such, this study used only questionnaire as a survey method to collect the data. So, further study should have multiple survey methods to collect information in details. Some of the respondents might not have honesty and seriousness to fill the questionnaire and hence this might have failed in giving the appropriate result. And finally understanding of the factor affecting staff turnover and job satisfaction will be useful for the organization, in order to manage and maintain the potential employees within the organization and decrease employee turnover rate which will be costly to the organization as whole.

\section{References}

Abeysekera, I. (2005). Managing human capital in a privately owned public hotel chain.International Journal of Hospitality Management, 25, 586-601.

Almeida, M. H. R.G., Faísca, L. M. M. \& Jesus, S. N. (2012). Positive attitudes at work, some of its consequents and antecedents: A study with hotel professionals. International Journal of Economics and Management Sciences, 6, 71-88.

American Hotel \& Lodging Association. (2014). Top ten issues in hospitality industry for 2015.

Beach, A. J. (2006). Empowerment to the people: creating an atmosphere for growth. Empowerment in organizations, 4(1), 29-33.

Armstrong, M \& Murlis, H (2007). Rewards Management: A Handbook of Remuneration Strategy and Practice. London. Kogan Pages Limited.

Berger, L.A. (2000). The compensation handbook: a state-of-the-art guide to compensation strategy. USA. McGraw-Hill, Inc.

Chand, M. \& Katou, A. A. (2007). The impact of HRM practices on organizational performance in the Indian hotel industry. Employee Relations, 29(6), 576-594.

Chen, C. (2006). Job satisfaction, organizational commitment, and flight attendant's turnover intentions: A note. Journal of Air Transport Management, 12, 274-276.

Chi, C. G. \& Gursoy, D. (2009). Employee satisfaction, customer satisfaction, and financial performance: An empirical examination. International Journal of Hospitality Management, 28, 245-253.

Dawson, M., Abbott, J. \& Shoemaker, S. (2011). The hospitality culture scale: A measure organizational culture and personal attributes. International Journal of Hospitality Management, 30, 290-300. 
Firth, L., Mellor, D.J., Moore, K.A. \& Loquet, C. (2004), 'How can managers reduce employee intention to quit?. Journal of Managerial Psychology, Vol.19, No.2, pp.170187.

Gallo, A. (2016). Harward Business Review. Retrieved from hbr.org: https://hbr.org/2015/11/a-refresher-on-regression-analysis

Golden, T. D. \& Veiga, J. F. (2008). The impact of superior-subordinate relationships on the commitment, job satisfaction, and performance of virtual workers. The Leadership Quarterly, 19, 77-88.

Gu, Z. \& Siu, R. C. S. (2008). Drivers of job satisfaction as related to work performance in Macao casino hotels. International Journal of Contemporary Hospitality Management, 21, 561-578.

Herzberg, F. (1959). The motivation to work.New York: Wiley.

Judge, T. \& Bono, J. (2001). Relationship of core self-evaluations traits-self-esteem, generalized self-efficacy, locus of control, and emotional stability-with job satisfaction and job performance: A meta-analysis. Journal of Applied Psychology, 86, 80-92.

Lee, G., Magnini, V. P., \& Kim, B. (2011). Employee satisfaction with schedule flexibility: Psychological antecedents and consequences within the workplace. International Journal of Hospitality Management, 30, 22-30.

Leite, C. \& Carvalho, R. (2011). Gestão da ergonomia para a saúde ocupacional dos gerentes hoteleiros. International Journal on Working Conditions, 1, 110-128.

Lockyer, C. \& Scholarios, D. (2004). Selecting hotel staff: why best practices does not always work. International Journal of Contemporary Hospitality Management, 16(2), 126-136.

Lucas, R. \& Deery, M. (2004). Significant developments and emerging issues in human resourcemanagement.International Journal of Hospitality Management, 23, 459-472.

Paul, A.K. \& Anantharaman, R.N. (2003). Impact of people management practices on organizational performance: analysis of a causal model. International Journal of HumanResource management, Vol.14, No.7, pp.1249.

Qu, H. \& Zhao, X. (2012). Employees' work-family conflict moderating life and job satisfaction. Journal of Business Research, 65, 2-28.

Rebouças, D., Legay, L. \& Abelha, L. (2007). Satisfação com o trabalho e impacto causado nos profissionais de serviço de saúde mental. Revista de Saúde Pública, 41, 244-250.

Rosenbloom, J.S. (2005). The Handbook of employee benefits: design, funding, and administration. USA. McGraw-Hill Companies, Inc.

Santos, A. \& Paiva, V. (2007). Vulnerabilidade ao VIH: Turismo e uso de álcool e outras drogas. Revista de Saúde Pública, 41, 80-86.

Sivasubramanyam, N. \& Venkataratnam, C.S. (1998). The Relationship between Human Resource Management and Firm Performance: The Indian Experience. Paradigm, 1: pp.135-141.

Sledge, S., Miles, A. K. \& Coppage, S. (2008). What role does culture play? A look at motivation and job satisfaction among hotel workers in Brazil. The International Journal of Human Resource Management, 19, 1667-1682.

Tabachnick, B.G. \& Fidell, L.S. (1996). Using multivariate statistics (3rd ed.). New York: Harper Collins.

Terpstra, D.E. \&Rozell, E.J. (1993). The relationship of staffing practices to organizational level measures of performance. Personnel Psychology, Vol.46, pp.27-48. 
Wright, P.M., Garden, T.M. \& Moynihan, L.M. (2003). The impact of HR practices on the performance of business units. Human Resource Management Journal, Vol.13, No.3, pp.21-36.

www.ditutor.com.(2016). http://www.ditutor.com/regression/types_correlation.html. 